\title{
Sustainable Industrial Value Creation in SMEs: A Comparison between Industry 4.0 and Made in China 2025
}

\author{
Julian M. Müller,": and Kai-Ingo Voigt² \\ 1 Salzburg University of Applied Sciences, Urstein Süd 1, 5412 Puch bei Hallein, Austria \\ 2 Chair of Industrial Management, Friedrich-Alexander University Erlangen-Nürnberg, Lange Gasse 20, Nuremberg, 90403, Germany \\ \# Corresponding Author / E-mail: julian.mueller@fh-salzburg.ac.at \\ ORCID: 0000-0002-7372-2405
}

KEYWORDS: Industry 4.0, Industrial internet of things, Made in china 2025 sustainability, Triple bottom line, Small and medium-sized enterprises

\begin{abstract}
The Industrial Internet of Things (IIoT) confronts industrial manufactures with economic, ecological, as well as social benefits and challenges, referring to the Triple Bottom Line of sustainability. So far, research has mainly investigated its dimensions in isolation or economic aspects have not been compared with ecological and social perspectives. Further, research misses studies that are devoted to the special characteristics and requirements of Small and Medium-sized Enterprises (SMEs). This study aims to contribute to close this research gap, providing a research context that encompasses all three dimensions of sustainability. The results are based on data obtained from 329 SMEs, 222 in Germany and 107 in China, therefore allowing for a comparison of the concepts "Industrie 4.0" and "Made in China 2025" in the context of SMEs. In general, German SMEs expect a lower impact through "Industrie 4.0", perceiving the concept as more beneficial for larger enterprises. We further find that Chinese SMEs foremost see social benefits. Challenges whilst introducing "Industrie 4.0" by German SMEs as well as several frame conditions are perceived more relevant than for "Made in China 2025", as seen by Chinese SMEs. The paper closes with implications for research and practice based on these findings.
\end{abstract}

\section{Introduction}

The Industrial Internet of Things (IIoT) describes the integration of Internet of Things (IoT) technologies into industrial value creation. As a result, entirely digitized, interconnected, self-regulating, and decentralized industrial value chains shall be established. ${ }^{1-3}$ These are intended to counteract issues that industry faces today, e.g., shortened technology and innovation cycles, increasing customization demands, and enhanced demand volatility. Thereby, industrial manufactures shall be enabled to maintain and strengthen their global competitiveness. ${ }^{4}$

As the introduction of the IIoT not only arises potentials, but also risks for industrial manufacturers ${ }^{1,5}$ this paper is devoted to uncover their importance for industrial manufacturers. Numerous programs to introduce the IIoT have been developed worldwide. ${ }^{3}$ Hereby, Germany and China provide a fruitful research context. Both countries have structural differences, but a similarly high requirement for sustainable industrial value creation. ${ }^{6}$ In Germany, the program "Industrie 4.0 " is intended to introduce IIoT technologies within industrial value creation in order to maintain its position as a leading industrial nation in the world. ${ }^{1,3}$ As a result, industrial manufacturers will face with not only economic, ecological and social potentials, but also challenges. ${ }^{5,6}$ As proven in previous research articles, the Tipple Bottom Line of sustainability represents a suitable instrument in order to investigate the IIoT from the perspective of sustainability. ${ }^{5}$ In China, the program "Made in China 2025" also represents an attempt to introduce IIoT technologies within industrial value creation, but with a different purpose: reaching the position of a leading industrial nation worldwide. ${ }^{3}$ Similarly, potentials in the context of sustainability shall be achieved, but likewise, challenges will be faced. ${ }^{6}$ Additionally, this paper is devoted to specifically investigate Small and Medium-sized enterprises that play an important role for both, Germany and China, but so far have been less regarded in the context of the IIoT. ${ }^{7}$ Conclusively, this paper addresses the following research question:

How do SMEs perceive potentials and challenges in the context of 
sustainability through "Industrie 4.0" in Germany and "Made in China 2025" in China?

In the further course of this paper, chapter 2 describes the theoretical background, whereas chapter 3 outlines the current state of research. In chapter 4, the empirical approach is described, encompassing a survey with 329 SMEs, 222 from Germany and 107 from China. Chapter 5 presents the results of this survey, closing the paper with discussion and conclusion in chapters 6 and 7 .

\section{Theoretical Background}

When referring to the IIoT, the term "Industrie 4.0" or "Industry 4.0 " can often be observed in scientific literature." Industry 4.0 is derived from the "Industrie 4.0" initiative launched by the German government for ensuring future competitiveness of the German manufacturing industry. ${ }^{1,2}$ "Industrie 4.0" hereby describes the expectations of politics and industry associations that industrial manufacturing is heading towards the fourth Industrial Revolution. This revolution is intended to be realized via a high-grade digitization as well as the horizontal and vertical interconnection of industrial value creation, leading to intelligent and self-aware, smart industrial value creation. However, this estimation of "Industrie 4.0" being an outright Industrial Revolution remains disputed in practice, often being referred to as an evolution rather than a revolution ${ }^{7}$ The proceeding three Industrial Revolutions have achieved high productivity increases by socalled "General Purpose Technologies", namely mechanization, electricity, and IT. Their integration enabled large technical improvements and advances in industrial value creation. ${ }^{9}$ For Industry 4.0, CPS represent the underlying General Purpose Technology. ${ }^{8}$ Cyber-Physical Systems generate virtual processes next to physical ones to their mutual benefit, allowing real-time interconnection across entire supply chains. ${ }^{10}$ Thereby, significant advances in engineering, manufacturing, and supply chain management are expected, leading to new business models. These include, e.g., data-centric business models or platform-based business models, that are expected to generate new ways of value creation in industry. ${ }^{1,4,11,12}$

Additionally to the German initiative "Industrie 4.0", the EU initiated a program called "Factories of the Future" for sustainable production whilst maintaining global competitiveness. The "Industrial Internet Consortium" represents a comparable program in the U.S. which, in contrast to the German and European equivalents, is mainly driven by several founding members from industry rather than the government. ${ }^{13}$ In South Korea, a similar program with the aim to introduce digital technologies within industrial manufacturing is pursued under the title "Manufacturing Innovation 3.0", 14 among many further programs worldwide. ${ }^{3}$ In China, the government has indicated the program "Internet Plus" within the program "Made in China 2025". "Made in China 2025", released by the Chinese State Council in 2015, is an initiative to comprehensively upgrade the Chinese industry. The initiative draws direct inspiration from Germany's "Industrie 4.0" program. From 2015 to 2025, China's manufacturing industry is expected to match the development and efficiency levels of the leading industrial nations. The aim is to raise domestic content of core components and materials to $40 \%$ by 2020 and $70 \%$ by 2025 . In a third step, until the 100th anniversary of the founding of the People's Republic of China in 2049, China's position shall be established as the number one industrial power worldwide. ${ }^{15} \mathrm{~A}$ central distinction to other countries' programs is the government-controlled R\&D spending, ${ }^{16}$ which inflicts both benefits and challenges for the emergence and diffusion of technologies in China. ${ }^{17}$ In contrast to other countries, China has to leapfrog the achievements of the third industrial revolution to a several extend and still has lower automation levels than other industrial nations, ${ }^{18}$ relating to its fast development in the recent years. Whereas China's manufacturing industry accounted for just $2.7 \%$ of the global manufacturing industry in 1990 (9th place worldwide), by the year 2000 , this share had already grown to six percent (4th place worldwide). In 2010, with a share of $19.8 \%$, China achieved the largest share in industrial production worldwide. ${ }^{15}$ Still, efficiency levels of the Chinese manufacturing industry levels do not yet match those of Europe, the U.S., Japan or South Korea, making it an industrial supplier for many of those countries whilst achieving low shares of revenue. ${ }^{20-22}$ Further, an increased pressure towards environmental protection are encountered due to high resource consumption and environmental pollution of China's industry. ${ }^{21}$

Comparably to its three proceeding Industrial Revolutions, Industry 4.0 is expected to transform industrial production as well as society, ${ }^{23}$ aiming for economic, ecological and social benefits. ${ }^{5}$ Society increasingly expects industry to transform its value creation towards sustainability, ${ }^{24}$ i.e., to equally achieve economic, ecological, as well as social benefits, objectives referring to the Triple Bottom Line of sustainability. ${ }^{25}$ The Triple Bottom Line of sustainability is the outcome of a development since the World Commission on Environment and Development's "Brundtland report" in $1987,{ }^{26}$ which can be found today in the United Nations' Sustainable Development Goal 12 "Ensure sustainable consumption and production patterns". As a result, societal expectations towards decreasing environmental impacts of industrial manufacturing steadily increased, not solely focusing on profit maximization. ${ }^{27,28}$ In response, numerous Corporate Social Responsibility approaches within industrial enterprises have been developed, ${ }^{29,30}$ so far mainly regarding environmental impacts. However, the Triple Bottom Line requires a holistic consideration of all its three dimensions to fully unfold its benefits. ${ }^{31}$

Further, we decided to focus research on SMEs, defining those as enterprises with up to 500 employees and an annual turnover up to 50 million Euro, according to the definition of the German Institute for SME research. ${ }^{32}$ For China, we use the same definition, thereby including companies with an annual turnover of up to approximately 400 million Yuan. As over 99 per cent of the companies located in the EU are SMEs which contribute a gross value added share of over 50 per cent of the European economy with over 60 per cent of jobs, ${ }^{33}$ research in the context of SMEs is of major importance. Representing a comparable importance in China, SMEs represent 97.9 per cent of enterprises, which contribute about 58 per cent of gross value added share.$^{34}$ Research on the IIoT so far mostly focuses on large enterprises, whereas research focused on SMEs is rather seldom, albeit all industrial value chains being largely dependent on SMEs contributing as suppliers. ${ }^{7}$ Therefore, research on SMEs in the context of "Industrie 4.0" respectively "Made in China 2025" provides a research setting with high practical relevance. SMEs also proved to have adopted ERP 
systems differently than large enterprises ${ }^{36}$ representing a technological foundation of the IIoT. ${ }^{1}$ Consequently, research needs to address the distinct requirements and conditions present in SMEs regarding "Industrie 4.0" respectively "Made in China 2025", e.g., lower digitization levels, owner-centered strategic orientation and more flexible organizational structures. ${ }^{37}$ Further, SMEs typically have a single and focused business model that allows for statements that are generalizable for the entire organization. In larger organizations, which simultaneously employ several business models in different business divisions, ${ }^{7}$ statements are limited to the perspective of an informant which cannot capture the entire organization. Adding to large economic importance of SMEs and comparably less research in this field, we claim that SMEs are especially suitable to be investigated with surveys encompassing a single informant per firm.

\section{State of Research}

The current state of research mainly consists of publications that examine the relatively young research field of the IIoT from a technical perspective. ${ }^{4,38}$ Most studies concerning the field of sustainability do not provide a comprehensive overview in all three dimensions of sustainability, but rather describe single and specific aspects without its interconnection with the other dimensions of sustainability. However, adjusting and balancing these dimensions against each other is crucial for successful technology adoption and diffusion. Researchers claim that focusing solely on economic benefits within considering ecological and social aspects is tolerated decreasingly by society. Therefore, economical benefits, foremost market success, can be increased when initiating a new technology by including as well as promoting the consideration of ecological and social perspectives. ${ }^{39,40}$ Within the IIoT, digitization and interconnection of industrial processes assisted by data analytics, machine learning, and artificial intelligence, shall lead to potentials in all three dimensions of sustainability. ${ }^{5,41}$ However, those are accompanied by several challenges, especially in the implementation phase of the IIoT, that also refer to all dimensions of sustainability. ${ }^{5}$

When regarding the economic perspective of the IIoT, process transparency and interconnection allows their optimization. ${ }^{42}$ Thereby, efficiency, flexibility, quality and customization can be enhanced ${ }^{1,2,10}$ By increasing process transparency in intra- and inter-firm logistics, ${ }^{43}$ lead and storage times can be reduced, leading to decreasing logistics costs. ${ }^{44-46}$ Also, new business models emerge through data-based products and services ${ }^{4,47}$ as well as equipping existing production equipment for a transformation in CPS, also known as "retrofitting". ${ }^{12,48}$ However, such processes as well as the implementation of the IIoT in general poses threads regarding large investments required with uncertain profitability. ${ }^{1,7}$ Further, established manufacturers fear to lose their existing market position to new entrants, as current business models are challenged and need to be adapted. Also, especially SMEs regard the high investments into IIoT technologies, alongside further challenges, as too challenging whilst potentials are regarded foremost for larger enterprises, that in their view cannot compensate for the risks to be encountered.

When referring to the ecological dimension of sustainability, the IIoT enables ecological benefits in multiple dimensions. ${ }^{49}$ Through intelligent scheduling of tasks and processes enabled by demand and process transparency, load balancing can be optimized that leads to energy consumption reductions. ${ }^{50-52}$ Further, energy consumption reduction can be achieved through process simulation, ${ }^{53}$ prediction of energy consumption that leads to smart energy management in manufacturing. ${ }^{54}$ Also, manufacturing design can be achieved through data flowing back from usage to design, ${ }^{55}$ leading to improved product lifecycle management, including recycling processes. ${ }^{56}$ Thereby, the IIoT assists to reduce greenhouse gas emissions, providing carbon footprint analyses enabled by data transparency. ${ }^{42}$ By the same means, reduction of waste and resource consumption shall be established. ${ }^{57}$ This also applies to recycling of resources and tools as well as retrofitting of machines. ${ }^{55}$ Turning to logistics processes, reduction of transport of goods and unnecessary material flows are a major advantage. ${ }^{58}$ Wrong deliveries, unnecessary waiting time, and damaged goods can be reduced by data transparency throughout the entire supply chain. ${ }^{59}$ As intended by several programs such as "Industrie 4.0", reshoring reduces transport distances based on relocating production closer to where products and production equipment are required, further reducing logistics costs and environmental impact. ${ }^{5}$ Economic growth that is acquired by establishing new production facilities can then be modeled with a sustainability perspective from the beginning. ${ }^{60}$ Ecological challenges still remain unclear and are hardly investigated in the context of the IIoT. Mostly relating to disciplines such as computer science or data processing, authors claim that IIoT-enabled smart factories increasingly have to be investigated regarding energy usage as well as waste production..$^{54,58,60}$ Both aspects are hardly mentioned in current IIoT-related literature, but should receive increasing attention in the future.

Regarding the social dimension of the IIoT, several benefits for employees shall be achieved, e.g., measures for fair wage definition, human learning through intelligent assistance systems as well as human machine interfaces that lead to increased employee satisfaction in more socially-beneficial industrial workplaces. ${ }^{5,6}$ On the other hand, the current body of literature is largely disagreeing on whether the IIoT will inflict an increase or decrease of jobs. ${ }^{63}$ Figures in this context are varying widely and are partly contradictory. ${ }^{5,6}$ In general, it is expected that further automation of simple tasks will proceed, whereas job profiles emphasizing monitoring, collaboration, and training continue to be required in industry. However, several tasks of planning and monitoring as well as decision-making will fall to autonomous systems, therefore also replacing jobs in this area. ${ }^{60} \mathrm{~A}$ shift in society is expected as novel job profiles, often relating to data-analysis and IT-related workplaces, are emerging, while established workplaces, relating to mechanical labor, will decrease. ${ }^{5}$ Therefore, education and training have to be adjusted ${ }^{5,61}$ before and during the job. Further, organizational implementation of the IIoT requires organization transformation processes, often referred to as "digital transformation", that requires new mindsets as well as employee acceptance throughout the enterprise. .,62,63 $^{-1}$

The only studies so far that investigate several dimensions of sustainability within a common empirical study are Beier et al.(2017), ${ }^{6}$ Müller et al.(2018), ${ }^{63}$ Kiel et al.(2017). ${ }^{5}$ Hereby, Beier et al.(2017) focus on ecological and social aspects and regard economic aspects just marginally. Further, their study implies German and Chinese enterprises, but only marginally includes SMEs. The study of Müller et 


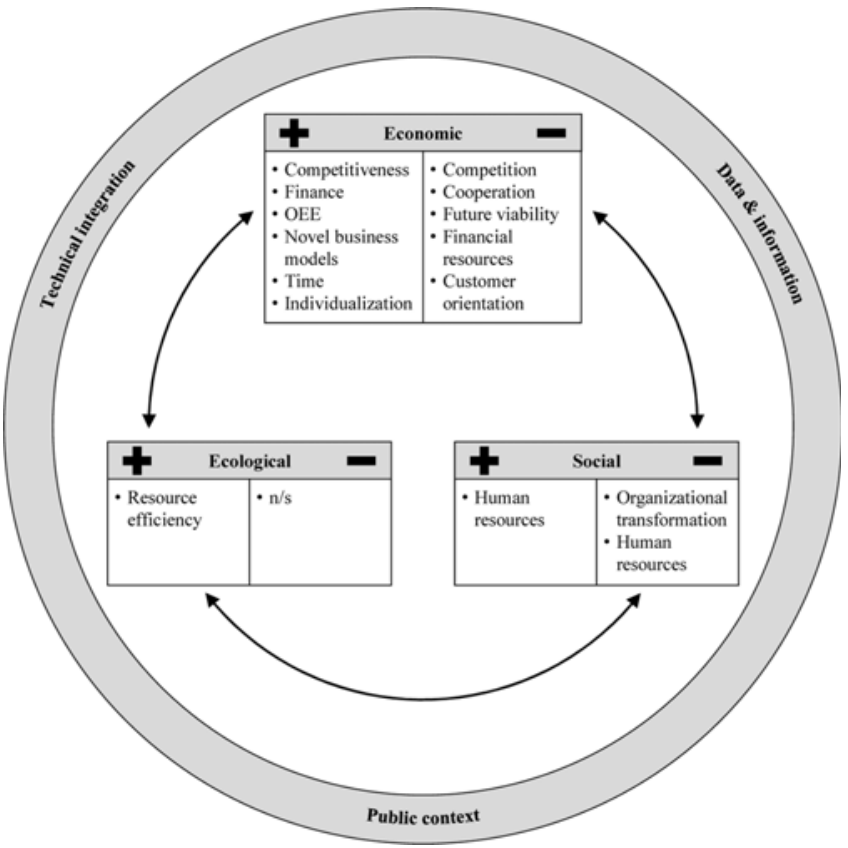

Fig. 1 Extended Triple Bottom Line for the IIoT by Kiel et al.(2017)

al.(2018) is able to derive distinct characteristics that delineate SMEs from larger enterprises, but their study covers the Triple Bottom Line of sustainability solely on a very general level, without going into specific subcategories. On the other hand, Kiel et al. develop a framework for the IIoT based on 46 expert interviews in Germany, extending the Triple Bottom Line by three aspects most commonly named: "Data and information" referring to data processing and analysis capabilities, "Public context" describing requirements in terms of legal framework and standardization, and "Technical integration", referring to intra- and intercompany implementation of the IIoT. ${ }^{5}$ As the study by Kiel et al.(2017) provides the only comprehensive overview of all three dimensions of sustainability, which however only refers to qualitative expert opinions, we further use and operationalize their model for our study design. Fig. 1 shows the extended Triple Bottom Line developed by Kiel et al.(2017).

\section{Method}

The study aims to derive potentials and challenges for SMEs from "Industrie 4.0" in Germany respectively "Made in China 2025" in the context of sustainability. To gain a comprehensive understanding of sustainability aspects regarding the IIoT, the extended Triple Bottom Line of Kiel et al.(2017) was operationalized using 5 point Likert scales. Whereas economic potentials and challenges are operationalized with one item each as described by Kiel et al.(2017), the authors decided to operationalize ecological and social potentials and challenges, originally only represented by one category, with two items each. Therefore, the two single dimensions by Kiel et al.(2017) were divided into two main categories, following their description of the dimensions. ${ }^{5}$ Thereby, the authors aim to obtain a more balanced understanding between the different categories within the Triple Bottom Line of sustainability. The same applies for the additional dimensions of "Technical integration", "Data \& Information", as well as "Public context", which are operationalized by two items each. The detailed questionnaire can be found in the appendix.

First, the questionnaire was translated from German into Chinese by master students from China completing their master courses in Germany. Second, the translation was discussed and improved with academic staff in China, both profound in German and Chinese, as well as potential recipients of the questionnaire. Third, the questionnaire was translated back into German by Chinese academic staff in order to ensure equality of terms. ${ }^{64}$ The term "Industrie 4.0 " was replaced by "Made in China 2025" for Chinese recipients. At the beginning of the questionnaire, the participants were given a brief explanation of the terms "Industrie 4.0" in Germany and "Made in China 2025" for Chinese participants, following the understanding of Kagermann et al. (2013) of "Industrie 4.0". For the Chinese questionnaire, the description was translated by the Chinese research partners and slightly adapted in order to match different characteristics between the two programs in accordance with the Chinese research partners.

German SMEs were randomly selected from the company database Bisnode, whereas Chinese students completing their master degree in Germany approached SMEs in China. Companies were contacted either per email or via telephone between December 2016 and February 2017 and asked to return the questionnaire via email. In total, 716 SMEs were contacted in Germany and 249 SMEs in China. Thereby, 338 questionnaires were obtained, from which nine questionnaires were not filled out completely and had to be removed. As a result, 329 questionnaires remained, 222 from Germany and 107 from China. This resembles a response rate of about 31 per cent in Germany and approximately 43 per cent in China.

Within the sample of 329 SMEs obtained, 95 enterprises employ up to 50 employees, 171 enterprises employ between 50 and 249 employees, whereas 63 enterprises employ between 250 and 500 employees. From 329 SMEs, 71 enterprises belong to mechanical and plant engineering, 64 to metal processing, 59 to electrical and ICT engineering, 26 to plastics engineering, 26 are automotive suppliers and 15 SMEs belong to paper and textiles industries. 68 respondents did not state their industry due to reasons of anonymity or giving too general statements, e.g. "industry" or "manufacturing" from Chinese participants. Aiming for personnel that can make qualified statements regarding the entire enterprise and all three dimensions of sustainability, 158 respondents are CEOs of the respective SME, 43 are production or plant managers, 27 are from R\&D departments, 23 derive from finance and controlling departments and 20 are department heads who did not specify their department. Further, 18 respondents derive from sales, 18 from procurement and supply chain management, whereas three respondents each are from IT departments, human resources, as well as quality management. Finally, 13 respondents did not state their exact function.

\section{Results}

\subsection{Impact of the IIoT on SMEs}

The results of the empirical data obtained indicate that whilst Beier et al.(2017) ${ }^{6}$ find a large perceived importance for both German and Chinese large enterprises, our results for SMEs indicate a lower perceived impact of the IIoT for their respective enterprise. Only about 


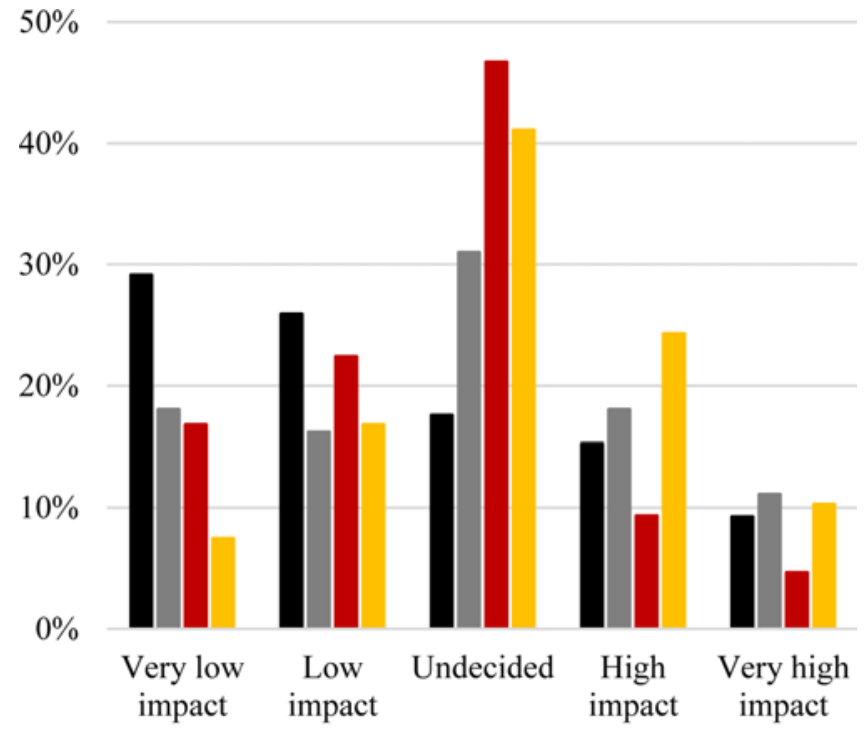

\section{Germany today \\ China today \\ - Germany in 5 years \\ China in 5 years}

Fig. 2 Perceived impact of the IIoT

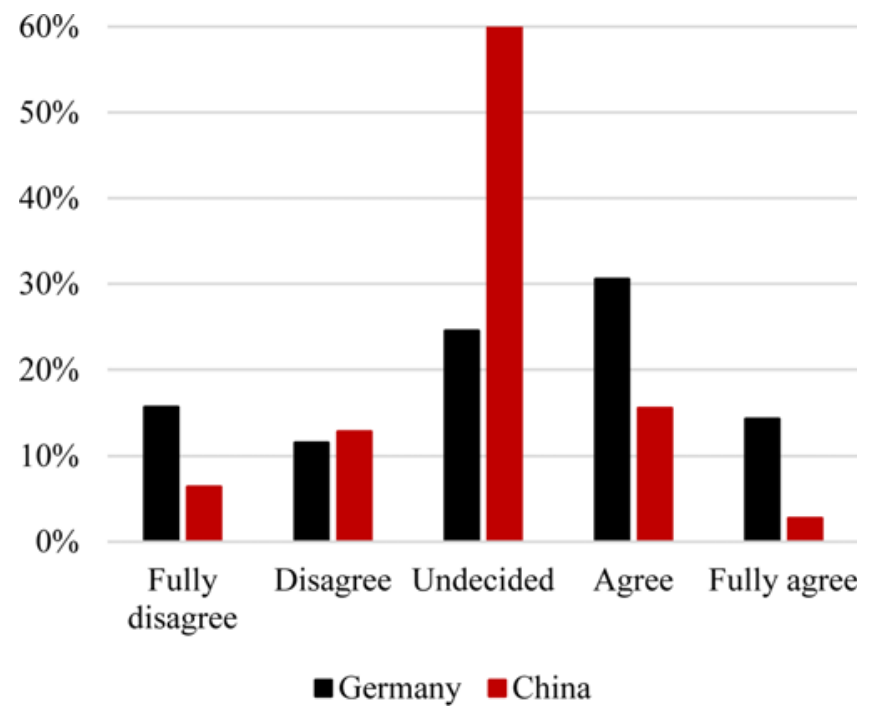

Fig. 3 Unsuitability of the current IIoT programs for SMEs

25 per cent of German SMEs expect a "high" or "very high" impact, whereas about 55 per cent of the German sample expect a "low" or "very low" impact and the present time. For Chinese SMEs, nearly 50 per cent expect a "low" or "very low" impact; only about 14 per cent expect a "high" or "very high" impact through the IIoT. Notably, approximately 47 per cent of SMEs in China are still "undecided" regarding the IIoT's impact today.

Confirming the findings of Beier et al.(2017) for large organizations, we find that in five years, Chinese SMEs expect a higher impact through the IIoT than German SMEs, but with lower absolute figures. In detail, only about 24 percent expect a "low" or "very low" impact in five years through "Made in China 2025", whereas in Germany, the same figure adds up to approximately 34 per cent. On the

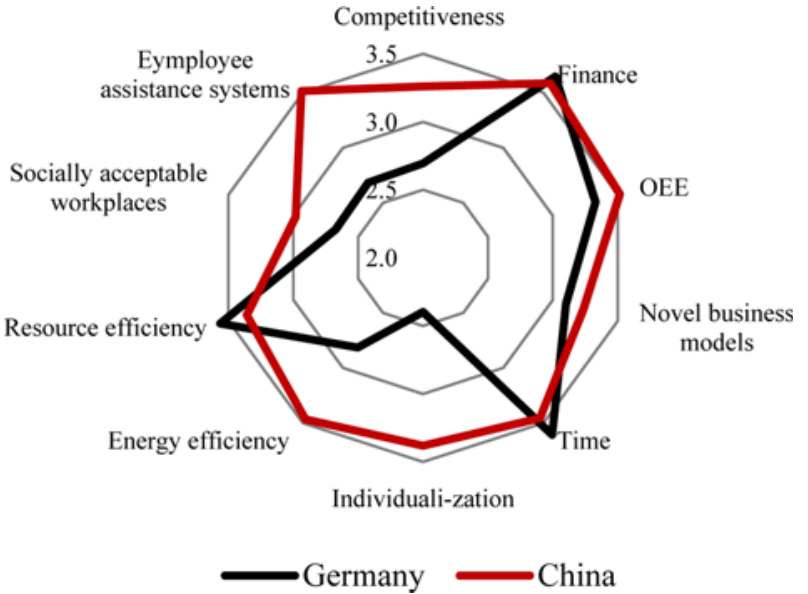

Fig. 4 Benefits of the IIoT in the context of sustainability

other hand, about 35 per cent expect a "high" or "very high" impact through "Made in China 2025" in five years, whereas this figure only amounts about 29 per cent for "Industrie 4.0". The detailed distribution can be obtained from Fig. 2.

As the authors expected a lower perceived impact through the IIoT for SMEs than for large organizations, a further question was introduced into the questionnaire. This question addresses claims that German SMEs might not feel as well addressed through "Industrie 4.0" in comparison to large enterprises, not being able to grasp its benefits as well as its large counterparts. ${ }^{7}$ In fact, about 45 percent of German SMEs within our sample "agree" or "fully agree" to this claim. For Chinese SMEs, the comparable figure for "Made in China 2025" only amounts to about 18 per cent. Further, about 60 per cent of Chinese SMEs rated this question as "undecided". Please see Fig. 3 for the detailed distribution.

\subsection{Potentials of the IIoT}

In this section, participants were asked to rate different potentials of the IIoT on five point Likert scales, ranging from 1, "fully disagree" to 5, "fully agree". The survey results indicate that overall, for Chinese SMEs, the IIoT, as represented by the program of "Made in China 2025 " promises to inflict larger potentials than for German SMEs within the program of "Industrie 4.0" (see Fig. 4 for mean values, please note that the scale is adjusted to improve readability).

Regarding economic potentials of the IIoT, the survey finds that competitiveness (Germany 2.69, China 3.26), i.e. the potential to derive completive advantages from the IIoT and individualization (Germany 2.40, China 3.38), i.e. to respond more individually to customer demands, are both foremost expected by Chinese SMEs. For financial benefits (Germany 3.65, China 3.59), i.e. generating larger revenues through the IIoT and benefits regarding time (Germany 3.61, China 3.46), i.e. shortening processes through the IIoT, German SMEs expect slightly higher potentials, but on a comparable level with Chinese SMEs. For overall equipment effectiveness (Germany 3.33, China 3.51), i.e. achieving higher efficiency and novel business models (Germany 3.10, China 3.23) emerging through the IIoT, potentials are expected higher from Chinese SMEs, but also on a comparable level. 


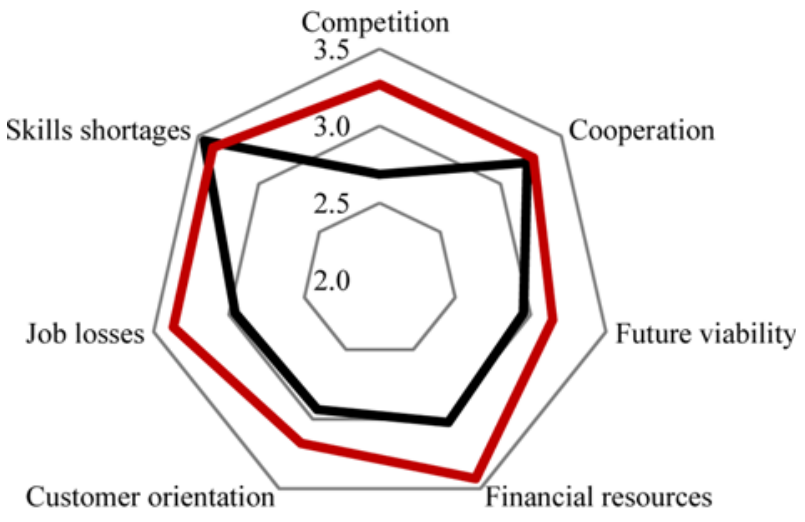

Germany China

Fig. 5 Challenges of the IIoT in the context of sustainability

For ecologic potentials of the IIoT, German SMEs show slightly higher expected resource efficiency (Germany 3.56, China 3.36), whereas increased energy efficiency is expected significantly higher by Chinese SMEs (Germany 2.81, China 3.47).

Social potentials of the IIoT are foremost regarded by Chinese SMEs, who expect benefits through employee assistance systems (Germany 2.68, China 3.51). The evaluation of more socially acceptable workplaces (Germany 2.67, China 2.98) are lower for both countries, however, still with a higher value for Chinese SMEs.

\subsection{Challenges of the IIoT}

Similar to potentials of the IIoT, participants were asked to rate different challenges on five point Likert scales, ranging from 1, "fully disagree" to 5, "fully agree". The empirical results show that in general, challenges are expected higher from Chinese SMEs than from German SMEs, except for challenges regarding skills shortages (Germany 3.45, China 3.38), i.e. difficulties to find adequate staff required for "Industrie 4.0 ", which are on a comparable level. The second social dimension of social challenges, job losses following IIoT implementation (Germany 2.96, China 3.37) is rated on a slightly higher level for "Made in China 2025 " in comparison to "Industrie 4.0".

Regarding the economic dimension of sustainability, challenges regarding cooperation (Germany 3.22, China 3.27), i.e. finding the right partners and suppliers for the IIoT are expected almost equally in both countries. Challenges regarding competition (Germany 2.69, China 3.27), i.e. market entrance of new competitors whilst losing the own competitive position, is foremost expected by Chinese SMEs. Challenges of future viability of the existing business model (Germany 2.95, China 3.15), adequate financial resources to implement the IIoT (Germany 3.02, China 3.43), loss of customer orientation (Germany 2.93, China 3.17) due to changing demands towards the IIoT are evaluated slightly higher by Chinese SMEs. Fig. 5 shows the detailed overview for mean values, as for Fig. 4, the scale is adjusted to improve readability.

\subsection{Additional Aspects Regarding the IIoT}

The importance of further dimensions as derived in the framework by Kiel et al.(2017) was also addressed by rating five point Likert
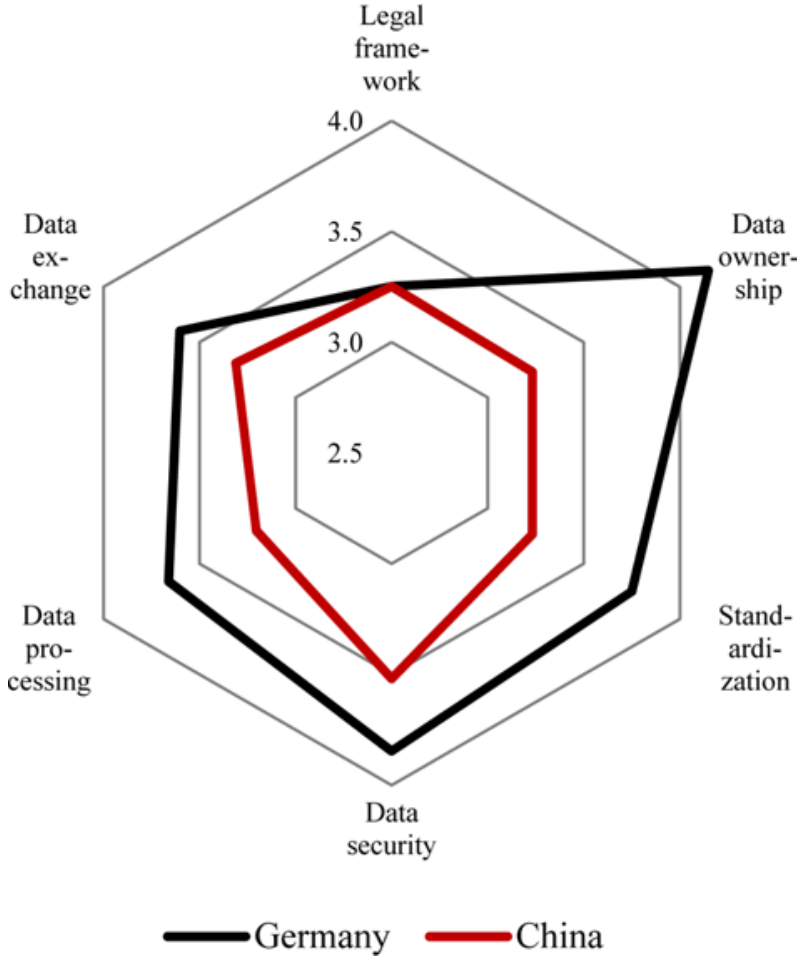

Fig. 6 Additional aspects accompanying the Triple Bottom Line

scales, ranging from 1 "fully disagree" to 5 "fully agree". In general, German SMEs expect comparable or higher importance for all six items. Regarding the dimension "Public context", the importance of a legal framework (Germany 3.25, China 3.25) that ensures data security and dependable legal conditions for data exchange, is rated equally important by participants in both countries. For the second item of "Public context", the question of data ownership (Germany 4.15, China 3.23) when interchanging data, especially on platforms, is rated significantly higher by German SMEs.

For "Data and Information", both requirements towards standardization (Germany 3.75, China 3.23) of, e.g. regulation for common interfaces, and standards when connecting ERP systems, as well as ensuring data security (Germany 3.85, China 3.52), i.e. technical means such as encryption of data, is seen more important by German SMEs.

Regarding "Technical integration", capabilities for data processing (Germany 3.66, China 3.20) towards, e.g. data acquisition of conventional machines through sensors, as well as data exchange (Germany 3.60, China 3.31), i.e. interconnecting products, machines and people, is seen slightly higher in Germany.

In the following, Fig. 6 shows the mean values for the three further dimensions regarding the IIoT (please note adjusted mean values for improved readability).

\section{Discussion}

The survey results reveal several interesting insights regarding sustainability through "Industrie 4.0" and "Made in China 2025" in SMEs. First, our study finds that in contrast to larger organizations, SMEs seem to evaluate the impact of the two programs lower, thereby 
providing an insightful comparison to the findings of Beier et al. (2017). ${ }^{6}$ Complementing the findings of Beier et al.(2017) in the context of SMEs, we reveal that Chinese SMEs expect a larger impact through "Made in China 2025" than German SMEs through "Industrie 4.0". Further, we find empirical evidence of a claim of German SMEs, that "Industrie 4.0" might be designed more towards the requirements of larger enterprises. Its benefits therefore might be harder to capture for German SMEs than for Chinese SMEs. In response, several German governmental institutions in association with industry alliances have already launched different programs in order to better integrate German SMEs within "Industrie 4.0". For example, the German Ministry for Economic Affairs and Energy has launched the imitative "Mittelstand 4.0", whereas the Ministry for Economic Affairs, Labor and Housing of Baden-Württemberg has initiated the program "Allianz 4.0". Both programs aim for the specific requirements of SMEs regarding "Industrie 4.0 ", e.g. small-scale solutions and also relate to economic, ecological and social aspects. However, application examples from practice, as well as underlying studies mostly relate to enterprises with up to 2500 employees, often related to as "Mittelstand" in Germany, and even mention to not explicitly focus on SMEs with up to 250 or 500 employees. ${ }^{67}$ Therefore, the authors recommend to increasingly and specifically regard SMEs, which as such have a high importance for the German economy and have even more specific requirements due to their small size. Relating to another aspect, the higher digitization levels established in the German industry in comparison to China might hereby skew our results, German SMEs therefore seeing "Industrie 4.0" as a smaller step than Chinese SMEs regard "Made in China 2025."

This interpretation succeeds for the perceived benefits of SMEs through the IIoT. Whereas Chinese SMEs expect a more or less evenly distributed set of economic, ecological and social benefits through "Made in China 2025", Germany SMEs, with few exceptions, evaluate the potentials for "Industrie 4.0" considerably lower. Regarding economic benefits, German SMEs foremost expect operational benefits, such as financial profits, time savings, and a comparably high evaluation of Overall Equipment Effectiveness in comparison to Chinese SMEs. Novel business models are the only benefit of a rather strategic dimension within economic benefits that is seen at a comparable level as Chinese SMEs. However, strategic benefits within the economic dimension relating to competitiveness and individualization are foremost seen by Chinese SMEs. We therefore conclude that German SMEs rather see benefits through an operational perspective when referring to "Industrie 4.0", whereas Chinese SMEs emphasize both strategic and operational economic benefits. We find three possible explanations for this: German SMEs could either be more focused on operational excellence than on strategic foresight, therefore further emphasizing these benefits. Second, the rather low evaluation of strategic potentials could relate to their lower evaluation of importance regarding the IIoT for them, seeing "Industrie 4.0" rather designed for large enterprises. New potentials in competitiveness and individualization might therefore require a program more closely designed for SMEs. ${ }^{6}$ Third, German SMEs could rather see their competitiveness and level of individualization offered to customers at a high level, therefore not expecting high benefits through "Industrie 4.0" in this regard. On the other hand, individualization and competitiveness gains might be targets that especially Chinese SMEs pursue in an international context, rather than being medium-tier suppliers with comparably high batch sizes and low individualization levels. For economic challenges regarding the IIoT, increasing competition and lack of financial resources is foremost seen by Chinese SMEs. The former aspect might be related to a backlog in comparison to other industrial nations, as outlined in the preceding section, which could arise fear of increasing competition by Chinese respondents. Lack of financial resources expected by Chinese SMEs might hereby be a result of central government R\&D spending, that is rather focused on larger enterprises. ${ }^{13}$ The challenges regarding cooperation, as well as losing customer orientation future business models are on an equal level for both countries, both potentially questioning the availability of adequate partners as well as the future viability of their business model designed to customer demands. ${ }^{23}$ For SMEs in both countries, these doubts might rely on low digitization levels in comparison to larger organizations in the respective countries. ${ }^{6}$

Regarding ecological benefits, resource efficiency gained through the IIoT is expected higher for German SMEs, but still at a close distance from Chinese SMEs, whereas energy efficiency is foremost expected by Chinese SMEs. In this regard, we complement the findings of Beier et al.(2017), ${ }^{6}$ who found comparable levels of resource savings potentials for both material and energy for the Chinese part of their sample. Still, the evaluation of answers is lower for Chinese SMEs in our sample than the findings illustrated by Beier et al.(2017). Regarding energy savings potentials, we confirm the findings of Beier et al.(2017), who also find that energy saving through the IIoT is much more regarded by Chinese than by German SMEs. The reasons hereof could be comparable, as German industry already has implemented a much higher share of renewable energy and sustainable energy programs, whereas the Chinese industry is still lacking behind in these two aspects. "Industrie 4.0" might therefore not be seen as that much of a tool for energy savings in comparison to "Made in China 2025."

Considering social benefits of the IIoT, socially acceptable workplaces and benefits trough intelligent employee assistance systems are foremost expected by Chinese SMEs. As the Chinese industry still shows much lower levels of digitization and even automation than the German industry, ${ }^{12}$ benefits might hereby be expected considerably higher for "Made in China 2025". The same applies for working conditions, for which China still has a backlog in comparison to Germany. Therefore, "Made in China 2025" might be seen as a stronger tool for improving social conditions in industrial value creation. Still, the considerably lower evaluation regarding potentials intelligent assistance systems by German SMEs in comparison to the higher potentials expected by large German enterprises in the study by Beier et al.(2017) is worth discussing. It might be a results of a different perception regarding such systems of more traditionally-oriented SMEs in Germany, which do not recognize the exact benefits yet. For social challenges regarding the IIoT, job losses are rather expected by Chinese SMEs. This confirms the findings of Beier et al.(2017), ${ }^{6}$ who claim that lower digitization levels in the Chinese industry in comparison to Germany comparably threatens more jobs. This claim is based on much larger plans to replace human workforce by automation in China than in Germany. ${ }^{12}$ As for skills shortages, the general shortage of skilled personnel in German SMEs might be exacerbated by the IIoT that requires even more IT-oriented jobs in traditional industries. ${ }^{6}$ 
For frame conditions accompanying the three dimensions of sustainability, both countries equally emphasize the requirement of dependable legal frame conditions, whereas the question of data ownership seems to be a more pressing issue for German SMEs. For the second, we reason that this evaluation has a cultural background, especially for SMEs, as German SMEs are eager to preserve their knowledge and trade secrets. ${ }^{6}$ On the other hand, Chinese SMEs might be influenced through data control and censorship by the Chinese state, providing a dependable, but restrictive legal framework $^{68}$ Second, standardization and data security are both emphasized more by German SMEs. Whereas the former aspect might be related to a higher level of standardization in China due to government control, ${ }^{12}$ data security might also have a cultural background, data privacy concerns being a much more relevant issue for the German society. Finally, capabilities referring to data processing and data exchange are again evaluated more relevant for German SMEs than for Chinese SMEs. Hereby, we reason that German SMEs might be at a more advanced level of digitization, therefore possibly already encountering a higher importance of these frame conditions in comparison to Chinese SMEs.

\section{Conclusion}

\subsection{Managerial Implications}

Drawing on the findings and discussion in the previous two chapters, we are able to derive several managerial implications. For "Industrie 4.0", we recommend German SMEs to consider the potentials of improving their competitive position and individualizing products to customers' demands. As both potentials are a core target of "Industrie 4.0", 1 SMEs should make sure not to miss opportunities in this regard. Likewise, the low perception of these two potentials should arise concerns for German governmental institutions and industry associations, adding to claims that "Industrie 4.0" might be more designed towards the requirements of larger enterprises. ${ }^{6}$ Therefore, adaptions or accompanying programs especially designed for SMEs should be considered, as neglecting SMEs on the path to "Industrie 4.0" cannot be afforded. Further, the potentials of energy efficiency through digitization and interconnection should be considered by SMEs, which might not be acquirable for them as a single organization, but as a part of an entire supply chain. Also, we encourage SMEs to further evaluate the potentials for supporting employees via intelligent assistance systems and designing workplaces that are more suitable for groups that require integration within industry in Germany, e.g. apprentices, elderly people, disabled persons and refugees. This could also, at least to a certain extent, address the skills shortages expected by German SMEs. Also, finding adequate partnerships, especially among SMEs, could help to amplify several potentials within all three dimensions of sustainability. For the German state, we recommend to address data security as well as data ownership concerns, relating to employee as well as company data. Further, providing a framework and recommendations for action regarding standardizing processes could be a valuable contribution for German SMEs for a sustainable integration of "Industrie 4.0".

For "Made in China 2025", Chinese SMEs overall see potentials in all three dimensions of sustainability, however expecting larger challenges regarding its implementation. In order to make sustainability potentials in Chinese SMEs accessible, concerns towards increasing competition, future viability as well as losing customer orientation should be addressed. Chinese SMEs hereby need to find new or modified business models that address these concerns. On the other hand, the Chinese state needs to provide solutions for lacking financial resources in SMEs in order to successfully introduce "Made in China 2025". Further, China is required to address two challenges in a common program: decreasing number of jobs in manufacturing SMEs, as well as skills shortages expected through introducing "Made in China 2025." Hereby, adequate measures for training, especially retraining of existing employees, need to be taken in order to ensure a sustainable introduction of "Made in China 2025". Albeit concerns towards data security and data ownership are evaluated of lower importance by Chinese SMEs in comparison to German SMEs, these aspects should not be neglected. Those demands, especially for employee data, might arise in the future, requiring adequate strategies for ensuring a sustainable introduction of "Made in China 2025" in the social dimension.

\subsection{Theoretical Implications}

This paper contributes to the scientific understanding of the IIoT, represented by "Industrie 4.0" in Germany and "Made in China 2025" in China. Therefore, this study adds to an international comparison between different IIoT programs, comparing Germany's program "Industrie 4.0", designed for maintaining Germany's position as an established industrial nation with China and its program "Made in China 2025", designed to become the leading industrial nation in the world. This comparison between both IIoT programs is further conducted in the context of sustainability. Thereby, this paper adds to the understanding of economic, ecological, as well as social benefits and challenges if the IIoT, aspects that have so far been mostly regarded in isolation. Also, the study is able to shed light on required frame conditions for successfully implementing the IIoT in both countries. Further, the currently less regarded, but important category of SMEs is investigated in both countries, adding to the rather sparse body of literature in the context of the IIoT and SMEs. Based on the model of sustainable industrial value creation by Kiel et al.(2017), its different subcategories are measured for both, German and Chinese SMEs. Thereby, this paper represents one of the first to quantitatively assess the concept of sustainability in the context of the IIoT. Based on these findings, several research avenues can be deduced, as outlined in the next section.

\subsection{Limitations and Future Research}

Naturally, our findings and subject to several limitations. First, our results can draw a picture on all three dimensions of sustainability regarding IIoT implementation. However, a comparison of interdependencies between those categories could not be established due to too few cases, especially regarding Chinese SMEs. Therefore, we recommend future research to consider these interdependencies, as they represent a vital part of strategy formulation for industrial manufacturers. Second, no ecological challenges could be uncovered by the model used of Kiel et al.(2017), which is why those are not included in our survey. However, ecological challenges could emerge 
by, e.g. increased energy consumption by data interchange, for which the relationship with energy saved by data interchange still remains unclear. A second example imaginable includes decreasing reusability by increasing individualization. Thus, we recommend future research to elaborate on ecological challenges. Third, several sub dimensions of challenges within the Triple Bottom Line are operationalized at a rather general level, referring to, e.g. loss of jobs. Hereby, a more detailed investigation regarding which job profiles emerge and which diminish, could be a valuable contribution. Fourth, whilst the work of Beier et al. (2017) represents a valuable comparison to our study, a single study encompassing SMEs and large enterprises would increase comparability of results. In a similar regard, extending the findings from Germany and China to other programs worldwide is a further promising research avenue.

\section{CONFLICT OF INTERESTS}

On behalf of all authors, the corresponding author states that there is no conflict of interest.

Funding Info: Open access funding provided by FH Salzburg University of Applied Sciences.

Open Access: The article published in this journal is distributed under the terms of the Creative Commons Attribution 4.0 International License (http://creativecommons.org/licenses/by/4.0/), which permits unrestricted use, distribution, and reproduction in any medium, provided you give appropriate credit to the original author(s) and the source, provide a link to the Creative Commons license, and indicate if changes were made.

\section{REFERENCES}

1. Kagermann, H., Helbig, J., Hellinger, A., and Wahlster, W., "Recommendations for Implementing the Strategic Initiative Industrie 4.0: Securing the Future of German Manufacturing Industry; Final Report of the Industrie 4.0 Working Group," Forschungsunion, 2013.

2. Lasi, H., Fettke, P., Kemper, H.-G., Feld, T., and Hoffmann, M., "Industry 4.0," Business \& Information Systems Engineering, Vol. 6, No. 4, pp. 239-242, 2014.

3. Liao, Y., Deschamps, F., Loures, E. D. F. R., and Ramos, L. F. P., "Past, Present and Future of Industry 4.0-A Systematic Literature Review and Research Agenda Proposal," International Journal of Production Research, Vol. 55, No. 12, pp. 3609-3629, 2017.

4. Arnold, C., Kiel, D., and Voigt, K.-I., "How the Industrial Internet of Things Changes Business Models in Different Manufacturing Industries," International Journal of Innovation Management, Vol. 20, No. 8, pp. 1640015-1-25, 2016.
5. Kiel, D., Müller, J. M., Arnold, C., and Voigt, K.-I., "Sustainable Industrial Value Creation: Benefits and Challenges of Industry 4.0," International Journal of Innovation Management, Vol. 21, No. 8, pp. 1740015-1-34, 2017.

6. Beier, G., Niehoff, S., Ziems, T., and Xue, B., "Sustainability Aspects of a Digitalized Industry - A Comparative Study from China and Germany," International Journal of Precision Engineering and Manufacturing-Green Technology, Vol. 4, No. 2, pp. 227-234, 2017.

7. Müller, J. M., Buliga, O., and Voigt, K.-I., "Fortune Favors the Prepared: How SMEs Approach Business Model Innovations in Industry 4.0," Technological Forecasting and Social Change, Vol. 132, pp. 2-17, 2018.

8. Veza, I., Mladineo, M., and Gjeldum, N., "Managing Innovative Production Network of Smart Factories," IFAC - PapersOnLine, Vol. 48, No. 3, pp. 555-560, 2015.

9. Bresnahan, T. F. and Trajtenberg, M., "General Purpose Technologies 'Engines of Growth'?," Journal of Econometrics, Vol. 65, No. 1, pp. 83-108, 1995.

10. Ivanov, D., Dolgui, A., Sokolov, B., Werner, F., and Ivanova, M., “A Dynamic Model and an Algorithm for Short - Term Supply Chain Scheduling in the Smart Factory Industry 4.0," International Journal of Production Research, Vol. 54, No. 2, pp. 386-402, 2016.

11. Oesterreich, T. D. and Teuteberg, F., "Understanding the Implications of Digitisation and Automation in the Context of Industry 4.0: A Triangulation Approach and Elements of a Research Agenda for the Construction Industry," Computers in Industry, Vol. 83, pp. 121-139, 2016.

12. Ehret, M. and Wirtz, J., "Unlocking Value from Machines: Business Models and the Industrial Internet of Things," Journal of Marketing Management, Vol. 33, Nos. 1-2, pp. 111-130, 2017.

13. Pike, J., "AT\&T, CISCO, GE, IBM and Intel Form Industrial Internet Consortium to Improve Integration of the Physical and Digital Worlds: Technology Leaders Drive Industry Ecosystem to Accelerate More Reliable Access to Big Data to Unlock Business Value," https://newsroom.cisco.com/press-release-content?articleId $=1375006$ (Accessed 10 JUL 2018)

14. Kang, H. S., Lee, J. Y., Choi, S., Kim, H., Park, J. H., et al., "Smart Manufacturing: Past Research, Present Findings, and Future Directions," International Journal of Precision Engineering and Manufacturing-Green Technology, Vol. 3, No. 1, pp. 111-128, 2016.

15. Tian, S. and Pan, Z., "Made in China 2025 und Industrie 4.0Gemeinsam in Bewegung," in: Industrie 4.0 Grenzenlos, Sendler, U., (Ed.), Springer, pp. 91-118, 2016.

16. Sun, Y. and Cao, C., "Demystifying Central Government R\&D Spending in China," Science, Vol. 345, No. 6200, pp. 1006-1008, 2014.

17. Fu, X., Pietrobelli, C., and Soete, L., "The Role of Foreign Technology and Indigenous Innovation in the Emerging Economies: Technological Change and Catching-Up,” World Development, Vol. 39, No. 7, pp. 1204-1212, 2011. 
18. Li, L., "China's Manufacturing Locus in 2025: with a Comparison of "Made-in-China 2025" and "Industry 4.0"," Technological Forecasting and Social Change, 2017.

19. Kennedy, S., "Made in China 2025," Center for Strategic and International Studies, https://www.csis.org/analysis/made-china-2025 (Accessed 10 JUL 2018)

20. Liu, S. X., "Innovation Design: Made in China 2025," Design Management Review, Vol. 27, No. 1, pp. 52-58, 2016.

21. Shubin, T. and Zhi, P., "Made in China 2025" and "Industrie 4.0" In Motion Together," in: The Internet of Things, Sendler, U., (Ed.), Springer, pp. 87-113, 2018.

22. Ceglowski, J. and Golub, S. S., "Does China Still Have a Labor Cost Advantage?" Global Economy Journal, Vol. 12, No. 3, 2012.

23. Maynard, A. D., "Navigating the Fourth Industrial Revolution," Nature Nanotechnology, Vol. 10, No. 12, pp. 1005-1006, 2015.

24. Elkington, J., "Partnerships from Cannibals with Forks: The Triple Bottom Line of 21st-Century Business," Environmental Quality Management, Vol. 8, No. 1, pp. 37-51, 1998.

25. Norman, W. and MacDonald, C., "Getting to the Bottom of Triple Bottom Line," Business Ethics Quarterly, Vol. 14, No. 2, pp. 243262, 2004.

26. World Commission on Environment and Development, "Our Common Future," Oxford University Press, http://www.worldcat.org/ title/our-common-future/oclc/15489268 (Accessed 10 JUL 2018)

27. Herrmann, C., Schmidt, C., Kurle, D., Blume, S., and Thiede, S., "Sustainability in Manufacturing and Factories of the Future," International Journal of Precision Engineering and ManufacturingGreen Technology, Vol. 1, No. 4, pp. 283-292, 2014.

28. Elkington, J., "Towards the Sustainable Corporation: Win-Win-Win Business Strategies for Sustainable Development," California Management Review, Vol. 36, No. 2, pp. 90-100, 1994.

29. McWilliams, A., Parhankangas, A., Coupet, J., Welch, E., and Barnum, D. T., "Strategic Decision Making for the Triple Bottom Line," Business Strategy and the Environment, Vol. 25, No. 3, pp. 193-204, 2016.

30. Glavič, P. and Lukman, R., "Review of Sustainability Terms and Their Definitions," Journal of Cleaner Production, Vol. 15, No. 18, pp. 1875-1885, 2007.

31. Littig, B. and Griessler, E., "Social Sustainability: A Catchword Between Political Pragmatism and Social Theory," International Journal of Sustainable Development, Vol. 8, Nos. 1-2, pp. 65-79, 2005.

32. IfM Bonn, "KMU-Definition," https://www.ifm-bonn.org/ definitionen/kmu-definition-des-ifm-bonn/ (Accessed $10 \mathrm{JUL}$ 2018)

33. Airaksinen, A., Luomaranta, H., Alajääskö, P., and Roodhuijzen, A., "Stafisfics on Small and Medium-Sized Enterprises. Dependent and Independent SMEs and Large Enterprises," Eurostat Statistics
Explained, http://ec.europa.eu/eurostat/statistics-explained/index.php/ Statistics_on_small_and_medium-sized_enterprises (Accessed 10 JUL 2018)

34. Jizhe, N., "China Statistical Yearbook - 2016," Compilted by National Bureau of Statistics of China, http:/www.stats.gov.cn/tjsj/ ndsj/2016/indexeh.htm (Accessed 10 JUL 2018)

35. Radziwon, A., Bilberg, A., Bogers, M., and Madsen, E. S., "The Smart Factory: Exploring Adaptive and Flexible Manufacturing Solutions," Procedia Engineering, Vol. 69, pp. 1184-1190, 2014.

36. Buonanno, G., Faverio, P., Pigni, F., Ravarini, A., Sciuto, D., et al., "Factors Affecting ERP System Adoption: A Comparative Analysis Between SMEs and Large Companies," Journal of Enterprise Information Management, Vol. 18, No. 4, pp. 384-426, 2005.

37. Aspara, J., Lamberg, J.-A., Laukia, A., and Tikkanen, H., "Corporate Business Model Transformation and Inter-Organizational Cognition: The Case of Nokia," Long Range Planning, Vol. 46, No. 6, pp. 459-474, 2013.

38. Brettel, M., Friederichsen, N., Keller, M., and Rosenberg, M., "How Virtualization, Decentralization and Network Building Change the Manufacturing Landscape: An Industry 4.0 Perspective," International Journal of Mechanical, Industrial Science and Engineering, Vol. 8, No. 1, pp. 37-44, 2014.

39. Hansen, E. G., Grosse-Dunker, F., and Reichwald, R., "Sustainability Innovation Cube - A Framework to Evaluate SustainabilityOriented Innovations," International Journal of Innovation Management, Vol. 13, No. 4, pp. 683-713, 2009.

40. Kuhl, M. R., Da Cunha, J. C., Maçaneiro, M. B., and Cunha, S. K., "Relationship Between Innovation and Sustainable Performance," International Journal of Innovation Management, Vol. 20, No. 6, Paper No. 1650047, 2016.

41. Hossain, M. S. and Muhammad, G., "Cloud-Assisted Industrial Internet of Things (IIOT)-Enabled Framework for Health Monitoring," Computer Networks, Vol. 101, pp. 192-202, 2016.

42. Peukert, B., Benecke, S., Clavell, J., Neugebauer, S., Nissen, N. F., et al., "Addressing Sustainability and Flexibility in Manufacturing Via Smart Modular Machine Tool Frames to Support Sustainable Value Creation,” Procedia CIRP, Vol. 29, pp. 514-519, 2015.

43. Schuhmacher, J. and Hummel, V., "Decentralized Control of Logistic Processes in Cyber-Physical Production Systems at the Example of ESB Logistics Learning Factory," Procedia CIRP, Vol. 54, pp. 19-24, 2016.

44. Hofmann, E. and Rüsch, M., "Industry 4.0 and the Current Status as Well as Future Prospects on Logistics," Computers in Industry, Vol. 89, pp. 23-34, 2017.

45. Zhong, R. Y., Huang, G. Q., Lan, S., Dai, Q., Chen, X., et al., “A Big Data Approach for Logistics Trajectory Discovery from RFIDEnabled Production Data," International Journal of Production Economics, Vol. 165, pp. 260-272, 2015. 
46. Zhou, W., Piramuthu, S., Chu, F., and Chu, C., "RFID-Enabled Flexible Warehousing,” Decision Support Systems, Vol. 98, pp. 99-112, 2017.

47. Kiel, D., Arnold, C., and Voigt, K.-I., "The Influence of the Industrial Internet of Things on Business Models of Established Manufacturing Companies-A Business Level Perspective," Technovation, Vol. 68, pp. 4-19, 2017.

48. Amshoff, B., Dülme, C., Echterfeld, J., and Gausemeier, J., "Business Model Patterns for Disruptive Technologies," International Journal of Innovation Management, Vol. 19, No. 3, Paper No. 1540002, 2015.

49. Sarkis, J. and Zhu, Q., "Environmental Sustainability and Production: Taking the Road Less Travelled," International Journal of Production Research, Vol. 56, Nos. 1-2, pp. 743-759, 2018.

50. Ding, K., Jiang, P., and Zheng, M., "Environmental and Economic Sustainability-Aware Resource Service Scheduling for Industrial Product Service Systems," Journal of Intelligent Manufacturing, Vol. 28, No. 6, pp. 1303-1316, 2017.

51. Fysikopoulos, A., Pastras, G., Alexopoulos, T., and Chryssolouris, G., "On a Generalized Approach to Manufacturing Energy Efficiency," The International Journal of Advanced Manufacturing Technology, Vol. 73, Nos. 9-12, pp. 1437-1452, 2014.

52. Weinert, N., Chiotellis, S., and Seliger, G., "Methodology for Planning and Operating Energy-Efficient Production Systems," CIRP AnnalsManufacturing Technology, Vol. 60, No. 1, pp. 41-44, 2011.

53. Herrmann, C., Thiede, S., Kara, S., and Hesselbach, J., "Energy Oriented Simulation of Manufacturing Systems-Concept and Application," CIRP Annals-Manufacturing Technology, Vol. 60, No. 1, pp. 45-48, 2011.

54. Shrouf, F. and Miragliotta, G., "Energy Management Based on Internet of Things: Practices and Framework for Adoption in Production Management," Journal of Cleaner Production, Vol. 100, pp. 235-246, 2015.

55. Chu, W.-S., Kim, M.-S., Jang, K.-H., Song, J.-H., Rodrigue, H., et al., "From Design for Manufacturing (DFM) to Manufacturing for Design (MFD) Via Hybrid Manufacturing and Smart Factory: A Review and Perspective of Paradigm Shift," International Journal of Precision Engineering and Manufacturing-Green Technology, Vol. 3, No. 2, pp. 209-222, 2016.

56. Zhao, W.-B., Jeong, J.-W., Do Noh, S., and Yee, J. T., "Energy Simulation Framework Integrated with Green ManufacturingEnabled PLM Information Model," International Journal of Precision Engineering and Manufacturing-Green Technology, Vol. 2, No. 3, pp. 217-224, 2015.

57. Stock, T. and Seliger, G., "Opportunities of Sustainable Manufacturing in Industry 4.0," Procedia CIRP, Vol. 40, pp. 536-541, 2016.

58. Gabriel, M. and Pessl, E., "Industry 4.0 and Sustainability Impacts: Critical Discussion of Sustainability Aspects with a Special Focus on Future of Work and Ecological Consequences," Annals of the Faculty of Engineering Hunedoara, Vol. 14, No. 2, pp. 131-136, 2016.
59. Qiu, X., Luo, H., Xu, G., Zhong, R., and Huang, G. Q., "Physical Assets and Service Sharing for IoT-Enabled Supply Hub in Industrial Park (SHIP)," International Journal of Production Economics, Vol. 159, pp. 4-15, 2015.

60. Meyer, B., Meyer, M., and Distelkamp, M., "Modeling Green Growth and Resource Efficiency: New Results," Mineral Economics, Vol. 24, Nos. 2-3, pp. 145-154, 2012.

61. Bonekamp, L. and Sure, M., "Consequences of Industry 4.0 on Human Labour and Work Organisation," Journal of Business and Media Psychology, Vol. 6, No. 1, pp. 33-40, 2015.

62. Tesch, J. F., Brillinger, A.-S., and Bilgeri, D., "Internet of Things Business Model Innovation and the Stage-Gate Process: An Exploratory Analysis," International Journal of Innovation Management, Vol. 21, No. 5, Paper No. 1740002, 2017.

63. Müller, J. M., Kiel, D., and Voigt, K.-I., "What Drives the Implementation of Industry 4.0? The Role of Opportunities and Challenges in the Context of Sustainability," Sustainability, Vol. 10, No. 1, p. 247, 2018.

64. Singh, J., "Measurement Issues in Cross-National Research," Journal of International Business Studies, Vol. 26, No. 3, pp. 597619,1995

65. Bischoff, J., Taphorn, C., Wolter, D., Braun, N., Fellbaum, M., et al., "Erschließen Der Potenziale der Anwendung Von "Industrie 4.0" im Mittelstand," Industrie, German Ministry for Economics and Energy, https://www.bmwi.de/Redaktion/DE/Publikationen/Studien/erschliessender-potenziale-der-anwendung-von-industrie-4-0-im-mittelstand.html (Accessed 10 JUL 2018)

66. Tan, J. and Tan, A. E., "Business Under Threat, Technology under Attack, Ethics under Fire: The Experience of Google in China," Journal of Business Ethics, Vol. 110, No. 4, pp. 469-479, 2012.

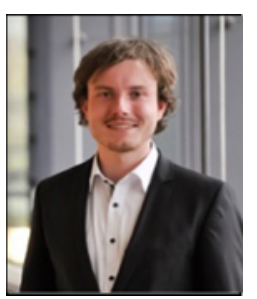

Julian M. Müller

Professor for Logistics and Operations Management, Salzburg University of Applied Sciences, Austria. His research interests include Industry 4.0, Sustainability, SCM and SMEs.

E-mail: julian.mueller@fh-salzburg.ac.at

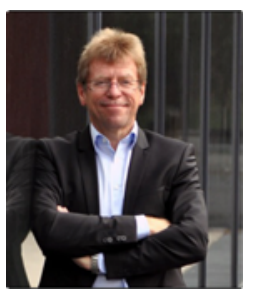

\section{Kai-Ingo Voigt}

Professor for Industrial Management, Friedrich-Alexander-University Erlangen -Nürnberg, Germany. His research interests include Industry 4.0 and technology \& innovation management. E-mail: kai-ingo.voigt@fau.de 


\section{APPENDIX}

\section{Item List}

\section{Fig. 2 Perceived impact of the IIoT}

"Industrie 4.0"/"Made in China 2025" has a significant impact for our business activities. ( $1=$ fully disagree, $5=$ fully agree $)$

Fig. 3 Unsuitability of the current IIoT programs for SMEs

"Industrie 4.0"/"Made in China 2025" tends to be designed for larger enterprises and is rather unsuitable for SMEs. (1 = fully disagree, 5 = fully agree)

Fig. 4 Benefits of the IIoT in the context of sustainability

"Industrie 4.0"/"Made in China 2025" helps our company to ...

... increase our competitiveness.

... improve the financial benefits of our operations (e.g., revenues).

... increase our Overall Equipment Effectiveness.

... generate novel business models.

... save time (e.g., in processes).

... offer more individualized products and services.

... increase our energy efficiency.

... increase our resource efficiency.

... improve the working conditions for our employees.

... introduce employee assistance systems for more comforting working conditions.

$(1$ = fully disagree, 5 = fully agree $)$

\section{Fig. 5 Challenges of the IIoT in the context of sustainability}

"Industrie 4.0"/"Made in China 2025" challenges our company through ...

... increased competition (e.g., through new market entrants).

... difficulties to find adequate partners that are required.

... threatening our company's future viability.

... required financial resources for its implementation.

... losing customer orientation (e.g., of products and services that are no longer required.)

... job losses within our workforce.

... skills shortages, as new competencies are required.

$(1$ = fully disagree, 5 = fully agree $)$

Fig. 6 Additional aspects accompanying the Triple Bottom Line

Please rate the importance of the following aspects regarding "Industrie 4.0"/“"Made in China 2025":

... dependable legal framework.

... data ownership.
... standardization (e.g., of processes and interfaces).

... data security.

... data processing capabilities.

... data exchange capabilities.

$(1=$ fully disagree, $5=$ fully agree $)$ 